to its extension that it soon becomes enclosed by a fibrous capsule, or calcifies and remains quiescent. From observing the very varying degrees of susceptibility to tubercular infection among the lower animals, we might naturally expect that there would exist among the individuals of the same order different degrees of sensibility to infection. Moreover, we must recollect that, though tuberculosis can be produced with certainty in the lower animals, the dose of the tubercular virus employed is generally relatively large, and by endermic or hypodermic inoculation is placed in the most favourable position for growth. It runs no risk of being swept away again, and is not injuriously influenced by gastric or intestinal secretions. And when infection has been produced by the inhalation of bacillus-containing fluids, the dose employed has been immeasurably larger than we can imagine would ever be the case in the accidental infection of human beings. Also in dogs, which are very insusceptible, tubercular infection cannot be produced with certainty by a small dose.

That tubercle in man is very frequently a local affection, never becoming general, is shown by the large number of cases of strumous disease of joints (now shown to be tubercular) which, under appropriate treatment, eventually recover without leading to general tubercular disease. Lupus, though now shown by Koch to be a tubercular affection of the skin, never leads to general tuberculosis. Numerous post-mortem examinations of bodies dead of other diseases reveal isolated tubercular deposits that have remained quiescent for years, and have had no share in causing death. Clinically, too, many cases are met with where the physical signs of tubercular disease of the lungs are found and incipient phthisis is diagnosed. When, however, they all, or in great part, disappear, and the patient regains robust health, the physician is apt to doubt his own diagnosis and to suppose that he has made a mistake. Such was frequently my own case till I read Dr. Austin Flint's admirable paper ${ }^{3}$ on the " Self-limited duration of Pulmonary Phthisis," where he calls attention to this point. These considerations, and the very remarkable differences in the course of tubercular disease in children and in adults, point to the supposition that all individuals do not afford an equally suitable soil for the growth of the tubercle bacillus, nor does the same individual at all times.

At present the diagnosis in the vast majority of cases has not been helped by the discovery of the tubercle bacillus, whatever may be the case in the future. It requires a considerable amount of skill to demonstrate the presence of tubercle bacilli, especially in sections of tissue; and although in good specimens and by a practised observer they may be recognised under a good $\frac{1}{4}$ in. objective, in doubtful cases a $\frac{1}{10}$ in., or preferably a $\frac{1}{12}$ in. homogeneous immersion is required. It was thought that the discovery of tubercle bacilli in sputum would prove of considerable diagnostic value, and would be employed clinically; but it must be remembered that the bacilli are not present in the sputum. till the tubercular deposit is breaking down and cavity formation has commenced, and then the diagnosis can generally be made from the symptoms and physical signs. Although the prognosis in tubercular diseases generally is much better than it used to be, that is owing to the great advance in treatment independently of, and in a large measure preceding, the discovery of the tubercle bacillus.

Though our treatment has suffered some alterations in consequence of the discovery of the tubercle bacillus, it is doubtful if it has been improved thereby. Various attempts have been made to introduce germicide remedies into the system, either by inhalation or by the mouth, with a view of destroying the bacilli. Hitherto all such attempts have been failures. Dr. Hassall ${ }^{t}$ has shown that the quantity of the antiseptic that enters the lungs in inhalation is so small as to be quite incapable of destroying the bacilli, much less their spores, which are so very much more resistant. This applies not only to the oro-nasal inhalers, but also to the method of inhalation by the vapour of hot water. By both methods beneficial effects are often produced, more especially in the way of allaying cough, but the action is probably chiefly on the larynx and trachea. As yet, also, no germicide has been found which can be administered in sufficient doses to render the fluids and tissues

3 Brit. Med. Jour.. vol. ii., p. 617, 1882

4 The Inhalation Treatment of Diseases of the Organs of Respiration, 4 The Inhalation Treatment of Diseases of the Organs of Respiration,
including Consumption. By Arthur Hill Hassall, M.D. 1885. including Longmans. of the body poisonous to the bacilli without at the same time proving hurtful, if not fatal, to the patient. Nor is it likely that any such substance will ever be discovered. Far more probable is it that such germicide medicines as quinine, corrosive sublimate, or arsenic may be administered in sufficient doses to render the fluids and tissues of the body an unfavourable soil for the bacilli, and so prevent their growing and multiplying, without being able to kill them, and also without proving harmful to their host. It is not unlikely, however, that in the future, as in the past, that treatment will be most successful which aims chiefly at increasing the general nutrition of the body. A high state of nutrition with an active circulation seems to be unfavourable to the growth of tubercle bacilli. Mainly by dietetic and hygienic measures the death-rate from phthisis for the decade 1861-70 has been diminished from that of 1851-60, at all groups of ages, and for the ten years 1871-80 the decrease has been still more marked, as seen in the chart in the preceding page. We may hope that with the recent advance in our knowledge of the pathology of tubercle, and with the great improvement in our methods of treatment the diminution in the death-rate from phthisis will continue to be progressive.

\section{TREATMENT OF URETHRAL STRICTURE BY ELECTROLYSIS.}

BY S. T. $\triangle$ N D ERSON, M.D.

IN a recent LANCET I read an article on Urethral Stricture, which inclines me to call attention to a different mode of treatment than that practised in the case referred to by Mr. Norton. I refer to the operation known as electrolysisi.e., electric analysis. We may better understand this matter if we bear in mind this fact that an equivalence exists between electric and chemical action. Attfield tells us that an electric force which will liberate from its combinations 127 parts of iodine will set free eighty parts of bromine. But this is exactly the proportionate work we expect from chemical analysis. Apply electric force in a proper manner to the tissues which produce the condition we call stricture, and disintegration results. The parts are not "burned out," as some infer, but the abnormal growth is resolved into its primary elements, is absorbed and permanently removed, whether the stricture be the result of injury or of the ordinary inflammatory causes. I cannot claim originality of method, and I must acknowledge my obligation to Dr. Robert Newman, of New York, for valuable advice. I know how electricity has been debased in public estimation by medical sciolists, and I have thought the results obtained in a few interesting operations performed by this strange potency might stimulate ambitious professional brethren to study and emulation. Presuming that results will be of greater interest, as they will doubtless be also of greater value, than theories, I will briefiy state the points in a few of the cases treated.

CASE 1.-Mr. H-_, aged about thirty, had a stricture developing slowly for a long time until catheterisation became needful, and later impossible. His physician informed him that the catheter could no longer be introduced, but the patient not crediting the statement, and believing the doctor did not use sufficient force, made an effort to introduce a metallic catheter, which, entering a pocket, was forced forward, making an opening into the rectum. In this condition he applied to Dr. Wm. Hill, a surgeon of this city, who brought the man to my office on July 18th 1884 On account of the passage made into the rectum we thought proper to administer chloroform, and then a No. 17 French electrode bougie slowly decomposed the stricture and entered the bladder in twenty-three minutes. The electrode was slowly withdrawn so as to more fully absorb the stricture tissue, and the instrument then passed quite easily. So soon as the chloroform effect had sufficiently subsided, the patient went into the street and passed unaided a good stream of water "about an hour" after the operation. No blood was lost in the operation, except that a few small clots escaped with wind from the rectum. The only complication which resulted was an orchitis a few days after he returned home to a neighbouring village, and the man remains well to this date--fifteen months after the operation. 
CASE 2.-J. --., aged thirty-two. This gentleman suffered from stricture for eight years, and a second one for about four years, The older one measured seven inches from the external opening, and the other an inch and a half. A No. 8 French sound would pass the lesser stricture, but nothing could be made to enter the bladder. He was obliged to rise for urination several times nightly, the urine slowly dribbling away from five to fifteen minutes, he said, and his clothes being constantly soiled by the oozing of urine by day. He was much emaciated and quite nervous. I operated on March 25 th, 1885, and finding the battery quite weak the current was gradually raised to sixteen cells. An electrode bougie (No. 14 French) worked its way into the bladder in thirteen minutes. During this time the patient lay on my operating chair conversing with me, and said he felt no pain. On beginning to arrange his clothing he expressed a a desire to pass urine, and as it flowed away in a good stream he brought his hand down on a table violently, declaring he would not take a million dollars for such a sensation-onehehad not experienced for years. Three weeks later 1 operated with a No. 17 French electrode, which, without force, passed through the strictures with a current from eleven cells in eight minutes. I have not seen the patient since his visit of July 5 th, but $I$ have reason to believe he remains cured of the stricture. I perhaps ought to add that he was making some physical improvement, despite nearly sixteen hours of daily toil.

CASE 3. This gentleman, aged forty, received an injury to the head and spine, growing out of which there was, at times, inability to void his urine, so that the catheter became necessary, and its use was followed by inflammation, especially in the anterior portion of the canal. No. 15 would enter the orifice to about half the length of the olive tip, but through the remainder of the glans a No. 6 French would barely pass. An operation was attempted on May 5th, 1885, but my electrodes would not pass without too much force; and when he came again, July 18th, the urethra could not receive a sound above No. 5 French, not larger than hair-pin wire. I carefully used at this date a No. 6 electrode bougie, with four electric cells, and on Aug. 7th a No. 8, with four cells. These operations gave much relief, but as he could only come at irregular intervals, the time of treatment has been somewhat prolonged. At present a No.11 instrument will pass with careful motion, and the man's health is improving, yet I shall enlarge the calibre somewhat more, and am confident of restoring the normal dimensions of the canal.

CASE 4.--In this case there had been a stricture for eight years in the posterior part of the canal, and one partially developed midway in the urethra. Lest I become tedious, I will speak only of the older obstruction. It had been cut and dilated, but healed, leaving an irregular opening. I could, by tedious manipulation, engage the point of a No. 8 sound, French gauge, in the oblique passage, but could not without violence enter the bladder. The urethra was exceedingiy irritable, and a sound discovered numerous pockets all along the passage. The patient gave a history of sounding and attempts at dilatation, which were annoying indeed. On August 8th, 1885, I operated with a No.9 electrode and a current from seven cells, giving considerable relief. The gentleman came again on September 13th, desiring speedy relief, expecting soon to move away. Because of the extremely unfavourable canal, I decided to have Dr. Hill join me in this operation, which was conducted under chloroform. A No. 12 bougie was made to absorb the strictures, so that the passage of the instrument became quite easy. As soon as he was fully awake he went, to his office to do some writing, and when I saw him four days later, he was doing well and said he had had no trouble. I have since then enlarged the urethra at the seat of the strictures, and improvement is continuous and Batisfactory.

From the foregoing it would seem that the treatment may be rapid by a single operation, or the result be obtained at several séances, and my experience thus far disposes me to agree with Dr. Newman in favour of the slower method. The special advantages of this method are apparent, yet I may mention two or three:-1st, anæsthetics are seldom necessary; 2ndly, no bæmorrhage; 3rdly, usually no pain ; 4 thly, ordinarily it does not interfere with business-for example, I operated on a railroad engineer in a certain afternoon, and at night he took his regular trip. So far, no failures have occurred.

Durley Theater, Blooming son, Illinois, U.S A.

\section{A CASE OF HYDROPHOBIA PRESENTING SOME PECULIAR SYMPTOMS.}

BY SURGEON J. CARTER BATTERSBY, M.B., ARMY MEDICAL DEPARTMETT.

IN THE LANCET of Sept. 1st, 1883, appeared a rery interesting case reported by Mr. C. J. Bond, house-surgeon, Leicester Infirmary. As some of the symptoms related bear a striking analogy to a case I saw some time ago, it may not be uninteresting to those who have had practical experience of the symptoms of hydrophobia to contrast the notes which I made when I saw the case with those reported by Mr. Bond.

On Thursday morning, June 4th, 1880, I was asked to see, in consultation with one of the civil medical officers of Clonmel, D. M- aged seventy, a strong, robust, healthylooking man, of temperate habits. On proceeding to the patient's house, his daughter informed me, in reply to $m y$ inquiries, that her father had been bitten on the upper lip and slightly on the nose by a pet terrier dog on Saturday evening, May 8th, 1880; the wound on the lip bled a good deal, and the patient sucked it for some time. About half an hour afterwards the lip and nose were cauterised with nitrate of silver.

On Tuesday morning, June 2nd (on the twenty-fourth day after receiving the bite), the patient got up in his usual good health, and on pouring the water into the basin in order to wash, he suddenly felt as though his arms were paralysed, and was unable to perform his customary ablutions. He immediately acquainted his family of the fact, and seemed perfectly conscious. Shortly afterwards he sat down to breakfast, and felt afraid to swallow either solid or liquid food, the slightest attempt to do so making him, as he says, "feel too nervous." The same day he went to bed, and, according to the evidence given by his daughter, commenced wandering in the most incoherent manner, imagining that some soldiers and a dog were in the room, his delusions sometimes making him believe that people or animals were outside of the ceiling, and that he could not get at them. When his own people entered the room he thought them changed in appearance.

On visiting the patient on June 4th, two days after the first symptoms had appeared, I found him sitting up in bed, apparently quite well and rational. After the customary salutation, he informed me, without being asked to do so, that my friend, the dispensary doctor, when visiting him the day before, had fanned him with his hat; that he (the patient) was much displeased with him for so doing, as "the fanning made him nervous." After a short time I noticed the patient beginning to speak in an incoherent manner, and having entered on some topic of conversation he seemed reluctant to let me leave until I had heard it all. While speaking, or even sitting quietly in bed, he would suddenly shudder, at the same time having drawn in a long inspiration, he seemed afraid to let the air out of his chest, and when so doing would produce a peculiar sound (which is most difficult to describe) resembling somewhat the word bou, his cheeks at the same time being much puffed out. The same phenomena were produced by drawing up the window blind. He felt confident that he would be "all right" by the following Monday, nerer to his recollection having been confined to bed through illness, his only complaint now being slight pain orer the heart and epigastric region. I brought him some milk in a cup and asked him to drink it, which he very reluctantlydid; at the same time I noticed that some spasmodic action was produced by so doing; about fifteen minutes before he had taken twenty-fice grains of hydrate of chloral. On examination I found that the wound on the lip had healed, and the patient did not fear any serious consequences from it. The tongue was clean and moist; pupils normal. Temperature $987^{\circ}$; pulse 120 and respiration 18 per minute. On Friday morning his condition was much the same as on the prerious dar. He told me he had "slept well during the night, and felt greatly better, but the thought of drinking anything made him feel quite nerrous." I now noticed that his roice had become hoarse and husky. About 7 o'clock on Friday evening I again saw the patient. His pulse, as on the previous dar, was 120 per minute, soft and regulai ; respiration 18 per minute; temperature $98.7^{\circ}$ The tongue was moist and slightly furred, the tip and edges 